\title{
Organização e práticas assistenciais: estudo sobre centro de atenção psicossocial para usuários de álcool e outras drogas
}

\author{
Organization and care practices: a study on \\ psychosocial care center for users of \\ alcohol and other drugs
}

Ana Lucia Marinho Marques ${ }^{1}$, Elisabete Ferreira Mângia² MARQUES, A. L. M.; MÂNGIA, E. F. Organização e práticas assistenciais: estudo sobre centro
de atenção psicossocial para usuários de álcool e outras drogas. Rev. Ter. Ocup. Univ. São Paulo,
v. 22, n. 3, p. 229-237, set./dez. 2011 .

RESUMO: Este artigo busca apresentar a organização e caracterizar as práticas desenvolvidas em um Centro de Atenção Psicossocial para usuários de álcool e outras drogas (CAPSad) com o objetivo de dar visibilidade a essa modalidade de serviço, de implementação recente no Brasil, que requer aprimoramento em seus diversos aspectos. Visa também refletir sobre as ações empreendidas para construção dos projetos terapêuticos dos usuários. Os conteúdos apresentados são parte integrante da dissertação "Itinerários terapêuticos de sujeitos com problemáticas decorrentes do uso de álcool em um Centro de Atenção Psicossocial". A pesquisa teve caráter qualitativo e foi desenvolvida no período de janeiro a março de 2009, no CAPSad "Travessia". Concluiu-se que o CAPSad deve funcionar como um serviço disponível e atento a gerar oportunidades de trocas de recursos materiais e afetivos e produzir, em conjunto com os sujeitos, o cuidado integral e centrado em suas necessidades.

DESCRITORES: Serviços de saúde mental; Usuários de drogas/psicologia; Alcoolismo/ psicologia.

1. Terapeuta Ocupacional do Curso de Terapia Ocupacional da FMUSP, Mestre pelo Programa de Pós-Graduação em Ciências da Reabilitação da FMUSP.

2. Profa. Dra. do Departamento de Fisioterapia, Fonoaudiologia e Terapia Ocupacional da FMUSP.

Endereço para correspondência: Departamento de Fisioterapia, Fonoaudiologia e Terapia Ocupacional - FMUSP Rua Cipotânea, 51, Cidade Universitária, São Paulo, SP, CEP: 05360-160. 


\section{INTRODUÇÃO}

$\mathrm{O}$ deslocamento do lócus de intervenção do atendimento centrado no hospital para serviços regionalizados, localizados mais próximos aos indivíduos atendidos, visa facilitar o acesso ao serviço e a identificação dos recursos disponíveis na comunidade. Entre os objetivos da atenção comunitária, encontramos a preocupação em promover e potencializar ações que visem o envolvimento de diversos atores no tratamento dos sujeitos atendidos, a fim de construir parcerias que visem à emancipação dos indivíduos, famílias e comunidades. Busca-se, assim, a participação efetiva do usuário, a parceria com familiares, o envolvimento da comunidade local e integração na atenção primária de saúde (OMS, 2001).

Essa abordagem também se aplica ao campo da atenção às pessoas com transtornos mentais severos $\mathrm{e}$ persistentes que integra, ainda, a questão da defesa dos direitos humanos. A abordagem centrada na comunidade é considerada efetiva e mais econômica e contribui com o aumento do protagonismo e a qualidade de vida das pessoas. Para tanto, deve ser composta por uma rede de serviços, articulados entre si, próximos a residência das pessoas, acessíveis e centrados nas necessidades dos sujeitos atendidos (OMS, 2001).

No Brasil, de acordo com esses princípios preconizados internacionalmente, observa-se a construção da Política Nacional de Atenção em Saúde Mental, que impulsionou o redirecionamento do modelo assistencial, com a implementação de uma rede de serviços, articulados entre si, que considerem a noção de território. O território compreende o espaço em que vivem as pessoas, suas instituições e os locais que freqüentam. Contempla, assim, um sentido singular, influenciado pelas diferentes culturas presentes em um mesmo espaço geográfico, cidade ou família (BRASIL, 2003).

É no contexto da construção de alternativas e modalidades de tratamento em saúde mental, que se inscrevem as propostas para o campo de cuidados para sujeitos com problemáticas decorrentes do uso de álcool e outras drogas, expressas pela primeira vez em 2003 na Política do Ministério da Saúde para a Atenção Integral a Usuários de Álcool e Outras Drogas. Dentre seus princípios norteadores estão: a atenção integral; a base comunitária; a territorialização; a lógica da redução de danos; e a intersetorialidade. Assume como objetivo a implementação de redes de atenção que privilegiem a inserção comunitária desenvolvida a partir de práticas de serviços extra-hospitalares em todos os níveis de atenção
(BRASIL, 2003, 2004c).

Para sua implementação, ganham destaque os Centros de Atenção Psicossocial (CAPS), que ocupam lugar central no processo de construção da rede de atenção substitutiva às internações em hospitais psiquiátricos. Os CAPS são serviços que devem se constituir como porta de entrada para a rede de cuidados em saúde mental, prestar assistência aos indivíduos que o utilizam, e articular a rede de serviços, organizando demandas e o direcionamento local de políticas e programas de saúde mental.

Esse artigo apresenta a caracterização e as práticas desenvolvidas em um CAPS para usuários de álcool e outras drogas (CAPSad) objetivando dar visibilidade a essa modalidade de serviço, que tem implementação recente no Brasil e que, portanto requer um percurso de avaliação e aprimoramento, especialmente diante do cenário atual de ampliação do debate em torno da questão do uso de substancias psicoativas, que tem desafiado diversos setores da sociedade na busca de alternativas assistenciais de cuidado, de apoio psicossocial e outras.

Nesta direção, pretende-se apresentar o serviço, alvo do estudo, a partir dos seguintes eixos: equipe e rotinas, acolhimento, gestão de caso, reuniões e espaços para trocas de informações; caracterização da população atendida e construção de projetos terapêuticos. Com isso se busca discutir aspectos considerados centrais para a elaboração de projetos terapêuticos singulares e centrados nas necessidades dos usuários.

Este estudo é parte integrante da dissertação "Itinerários terapêuticos de sujeitos com problemáticas decorrentes do uso de álcool em um centro de atenção psicossocial", defendida no Programa de Pós-Graduação em Ciências da Reabilitação da Faculdade de Medicina da USP e que visou conhecer os itinerários terapêuticos de sujeitos com problemáticas decorrentes do uso prejudicial de álcool em atendimento em um CAPSad. A pesquisa, de caráter qualitativo, adotou a perspectiva etnometodológica e empregou os procedimentos metodológicos de revisão bibliográfica, pesquisa documental, entrevistas semiestruturadas, grupo focal, observação participante e diário de campo. O trabalho de campo foi realizado no CAPSad "Travessia", no período de janeiro a março de 2009 (MARQUES, 2010).

A pesquisadora também possuía inserção anterior no serviço, tendo desempenhado ações como terapeuta ocupacional, por cerca de dois anos e meio. Essa inserção e o contato prévio com os usuários e profissionais, com suas singulares concepções e formulações práticas, além de despertar questionamentos e reflexões propulsores do 
estudo, favoreceu a entrada e a permanência no campo.

\section{O CAPSAD TRAVESSIA}

Na época de desenvolvimento do estudo, o município de Santana de Parnaíba apresentava uma rede de serviços de saúde mental comunitários e substitutivos às internações psiquiátricas de longa permanência composta por 1 CAPS II, 1 CAPSad (Álcool e Drogas), 1 CAPS Infantil, 1 Ambulatório de Saúde Mental e Adolescência, e equipes básicas de Saúde Mental lotadas em todas as Unidades Básicas de Saúde (UBS) e nas denominadas Unidades de Saúde Avançada (USA).

Nesta rede, o CAPSad "Travessia", serviço em funcionamento desde dezembro de 2004, colocava-se como referência para a prevenção, tratamento e reabilitação psicossocial dos sujeitos com transtornos decorrentes do uso prejudicial ou dependência de álcool, tabaco e outras drogas. Além das atividades relacionadas à assistência, o serviço buscava articulações intersetoriais e parcerias com outras instituições, públicas e privadas e promovia encontros para capacitação e sensibilização da população e das equipes de outros serviços de saúde.

O serviço funcionava de segunda à sexta-feira, das 7 às 19 horas. Durante todo o período em que permanecia aberto havia, no mínimo, um profissional da equipe técnica disponível para acolher, orientar, encaminhar os indivíduos que chegavam buscando tratamento, quer de forma espontânea, quer por encaminhamentos de outros serviços.

\section{Equipe e Rotinas}

Em janeiro de 2009, a equipe do serviço contava com 24 membros: um assistente social, um enfermeiro, um auxiliar e um técnico de enfermagem, um médico clínico geral, um médico psiquiatra, duas psicólogas, um terapeuta ocupacional, uma artesã, um chefe e um auxiliar administrativo, uma cozinheira, duas recepcionistas, dois auxiliares de limpeza, três vigias, um chefe e dois auxiliares de serviços gerais, um diretor técnico-administrativo. Esta composição correspondia aos parâmetros mínimos propostos pelo Ministério da Saúde para um CAPSad.

Os profissionais eram contratados com jornadas de trabalho diferenciadas (de 15 a 40 horas semanais) e não havia divisão por turnos. Mais da metade estava no serviço desde sua inauguração, e apenas dois, há menos de um ano.

A maior parte da equipe técnica, composta por 8 profissionais com ensino superior, dispunha de formação complementar na área de "dependências". Cinco em curso de especialização, e um em aconselhamento.

No geral, todos os profissionais da equipe técnica assumiam responsabilidades compartilhadas no desenvolvimento do conjunto das atividades assistenciais realizadas. Apenas a artesã era responsável apenas pela realização de oficinas terapêuticas.

Semanalmente, cada profissional era responsável pelo desenvolvimento de pelo menos um grupo terapêutico, educativo ou de orientação, por um período de plantão e pela gestão de casos. Cada profissional realizava também atividades correlatas à sua área de formação. As visitas domiciliares eram feitas, em sua maioria, pela assistente social e pela equipe de enfermagem.

Diariamente, eram realizados grupos, oficinas terapêuticas, consultas e atendimentos individuais específicos. Na época de realização da pesquisa eram desenvolvidos os seguintes grupos e oficinas: acolhimento, recepção, reflexão, psico-educacional, prevenção de recaídas, comunicação e cidadania, artesanato, horta, yoga/ lian gong, manutenção. Havia, também, um grupo de orientação familiar, no qual eram apresentados e discutidos aspectos relacionados à dependência de substâncias psicoativas, abordagens e tratamento. Estas atividades eram periodicamente reformuladas, de acordo com as demandas dos usuários e as possibilidades da equipe.

Para os usuários que frequentavam o serviço nos dois turnos, eram oferecidas até quatro refeições: café e lanche da manhã, almoço e lanche da tarde. As refeições eram preparadas na cozinha do serviço.

\section{Acolhimento}

Ao chegar pela primeira vez ao serviço a pessoa era acolhida por um profissional da equipe técnica presente em cada plantão. Esse atendimento consistia em uma entrevista, com o usuário (ou acompanhante) e visava conhecer e avaliar as necessidades de cuidado, para orientar a indicação da modalidade de tratamento mais adequada (intensivo, semi-intensivo ou não intensivo). Na modalidade intensiva era proposta a frequência diária e integral do usuário no serviço e participação em todas as atividades terapêuticas oferecidas. No regime semi-intensivo, o usuário deveria frequentar o serviço em dias e atividades selecionadas pela equipe. Já no modo não intensivo a freqüência ao serviço se restringia às consultas médicas, acompanhamento terapêutico individual ou outras atividades pontuais.

Não foi identificada fila de espera para inicio de tratamento (problema freqüentemente encontrado em serviços desse tipo) e quando havia encaminhamento para 
atendimento médico, as consultas eram agendadas no prazo médio de uma semana.

Na primeira semana de atendimento, propunha-se ao usuário a frequência diária no Grupo de Acolhimento, composto por cinco sessões pré-estruturadas, cada uma coordenada por um profissional, que abordava determinado tema de acordo com programação elaborada pela equipe. Os temas discutidos eram: critérios para o diagnóstico de dependência química; sintomas de abstinência; levantamento de fatores de risco e de proteção para o uso de substâncias psicoativas; mapeamento de redes sociais; apresentação do contrato com as regras do serviço. Em continuidade era iniciado o atendimento individual com o profissional que assumia a gestão do caso.

\section{Gestão de Caso}

A proposta de gerenciamento de caso, adotada no serviço, consistia em um conjunto de intervenções voltadas ao acompanhamento de cada sujeito. Ao gerente ou gestor de caso caberia: identificar as necessidades específicas do cliente; planejar e desenvolver uma proposta específica para cada cliente; estabelecer conexões com outros serviços (de saúde e outros); monitorar e avaliar cada caso, além de identificar os resultados obtidos e facilitar o amparo legal em caso de necessidade (FIGLIE; LARANJEIRA, 2004).

Uma vez que a equipe não recebeu instrução formal para desenvolvimento de ações como gestor de caso, os profissionais foram constituindo-se nesse papel a partir de sua própria prática cotidiana e por meio das discussões em reuniões de equipe. Nesse sentido, percebeu-se que ocorria uma redução da proposta de gerenciamento de caso e as funções do gestor acabavam limitadas, geralmente, apenas ao estabelecimento do plano terapêutico do usuário, que consistia na programação das atividades a serem realizadas como parte de seu tratamento, dentre aquelas oferecidas pelo serviço. Após discussão com outros profissionais da equipe, cada gestor de caso reavaliava periodicamente, junto com o usuário, sua participação nas atividades estabelecidas, refazendo seu plano terapêutico se necessário.

\section{Reuniões e trocas de informações}

A equipe técnica dispunha de uma reunião semanal, com duas horas de duração, para discussão dos casos atendidos e troca de informações relativas à organização do serviço. A comunicação entre os profissionais também ocorria no cotidiano do serviço e buscava-se registrar esses momentos em prontuários.

Os funcionários que não possuíam nível universitário não participavam de discussões de casos nem eram envolvidos nas ações terapêuticas. Também não existiam reuniões com a participação do conjunto da equipe. Essa dinâmica dificultava a constituição de uma linguagem compartilhada, a integração interna da equipe e a validação do papel e dos saberes dos profissionais de apoio.

Esporadicamente, eram realizadas assembléias que reuniam usuários e todos os profissionais, agendadas quando solicitadas por algum profissional ou usuário, ou quando se considerava que havia algum assunto importante a ser discutido coletivamente.

\section{Caracterização da população atendida}

Em janeiro de 2009, o serviço apresentava 606 usuários matriculados. Não foi possível calcular o número exato de prontuários ativos, pois a equipe não possuía claramente definidos os critérios para alta nem abandono. Também não eram excluídos os prontuários de óbitos e transferências para outros serviços.

No ano de 2008, a média mensal de ingresso de novos usuários foi de 15,3. Em dezembro daquele ano, havia 89 usuários freqüentando o serviço. Destes, 23 estavam inseridos na modalidade intensiva, 38 na semi-intensiva e 28 na não-intensiva (SANTANA DE PARNAÍBA, 2009).

\section{a) Droga de escolha}

Um dos critérios utilizados para avaliar e propor projetos terapêuticos partia da identificação da principal substância psicoativa consumida, pois se acreditava que esta definia a especificidade das necessidades apresentadas pelos usuários.

O estudo mostrou que a maioria dos usuários que procuraram o serviço apresentavam problemáticas resultantes do uso de álcool, representando $68,3 \%$ do total. $24,6 \%$ buscaram tratamento para dependência ou abuso de outras drogas, tais como cocaína, crack, maconha e benzodiazepínicos e 7,1\% procuravam tratamento para a dependência de tabaco. (Santana de Parnaíba, 2009).

\section{b) Gênero}

Do total dos usuários matriculados no serviço, $16,8 \%$ eram mulheres. Os dados referentes ao ano de 2008, mostram que dos 184 usuários novos, 46 (25\%) eram mulheres. Assim, verificou-se nesse período o aumento dessa demanda, que poderia estar associado à introdução de grupos específicos para tabagistas, compostos em sua maioria (75\%) por mulheres. 
$\mathrm{O}$ aumento na procura pela população feminina impulsionou a equipe a planejar o desenvolvimento de um grupo terapêutico direcionado exclusivamente a essa população por considerar que esta apresentava demandas singulares e requeria manejos específicos (SANTANA DE PARNAÍBA, 2009).

\section{c) Faixa etária}

Do total dos usuários matriculados ( $\mathrm{n}=606), 10,7 \%$ compreendia a faixa etária entre 18 e 25 anos; $24,1 \%$ entre 26 e 35 anos; $28,7 \%$ entre 36 a 45 anos; $22,8 \%$, de 46 a 55 anos e $13,7 \%$ com mais de 56 anos. A idade média era de 41 anos (SANTANA DE PARNAÍBA, 2009).

Os grupos e oficinas terapêuticas desenvolvidas eram direcionados aos usuários que se situavam na faixa etária média, restando poucos espaços que pudessem acolher os mais idosos e os jovens. Para o atendimento da população jovem e adolescente, buscavam-se parcerias com outros serviços do município.

\section{d) Encaminhamentos}

Outro dado analisado foi a forma de procura pelo serviço. Em um levantamento realizado entre os meses de agosto a dezembro de 2008 constatou-se que 46,1\% dos usuários buscaram espontaneamente o serviço. Neste quadro estão incluídos: busca própria, retornos e indicações de familiares ou amigos. Os serviços de saúde do município foram responsáveis por $43 \%$ dos encaminhamentos ao serviço. Destes, mais da metade $(54,5 \%)$ foram realizados pelos prontos-socorros (PAM Fazendinha e PAM Santa Ana). Os $10,9 \%$ restantes foram encaminhamentos provenientes de outras secretarias do município, outros municípios ou judiciais (SANTANA DE PARNAÍBA, 2009).

\section{e) Territorialidade}

O serviço possuía sistematização da distribuição dos usuários a partir de agrupamentos geográficos, correspondentes aos locais de moradia, em associação com as USA's e UBS's de cada território. Não existia o estabelecimento de relações de "referência", "contrareferência", "encaminhamentos", etc. A UBS "Álvaro Ribeiro", localizada no centro do município, era a referência para a maior parte dos usuários do serviço (29\%), compreendendo munícipes do centro e de diversos bairros adjacentes, próximos ao CAPSad. As UBS "Fazendinha" e "120" e a USA "São Pedro", todas localizadas no bairro Fazendinha, concentravam o maior número de usuários encaminhados, $40 \%$ do total (SANTANA DE PARNAÍBA, 2009).

Esse dado foi considerado importante na caracterização da população atendida pelo serviço, pois a observação da distribuição dos setores censitários, classificados de acordo com o grau de vulnerabilidade ao qual a população encontra-se exposta, baseada no IPVS (Índice Paulista de Vulnerabilidade Social), mostra que o território compreendido pelo bairro Fazendinha correspondia à área com o maior contingente populacional em situações de vulnerabilidade muito alta do município (FUNDAÇÃO SEADE, 2009).

Cabe acrescentar que o município apresenta uma extensão territorial considerável, e podia-se observar que, apesar de encaminhados, a maioria dos usuários que residiam em bairros mais afastados, apresentavam dificuldades em permanecerem participando das atividades propostas. Tal situação era pauta frequente das reuniões de equipe, que buscava meios para favorecer o acesso e permanência destes sujeitos no tratamento.

\section{A construção de projetos terapêuticos}

Neste tópico serão apresentados a visão geral do serviço combinada aos resultados da observação participante e dos casos estudados. Das narrativas compiladas, selecionou-se aquelas consideradas mais características da população atendida pelo serviço e representativas de seu percurso típico, buscando apreender seus pontos de força e aqueles que requerem aprimoramento e investimento.

Participaram do estudo oito usuários, escolhidos pela equipe, em atendimento no serviço por pelo menos 3 meses e que apresentavam uso prejudicial de álcool, com os quais foram desenvolvidos dois grupos focais e entrevista individual (MARQUES, 2010)

Embora os sujeitos chegassem ao CAPSad por diversas trajetórias, ao ingressarem no serviço encontravam uma mesma proposta de tratamento: cuidados intensivos nos primeiros 15 dias, com participação no Grupo de Acolhimento e atendimento médico, quando necessário. A equipe do serviço buscava manter este protocolo de início de tratamento pois compreendia que, para a maioria dos casos, este momento requer cuidados intensivos devido aos sinais e sintomas das síndromes de abstinência.

A proposta de cuidados em modalidade intensiva consistia, de forma geral, na freqüência ao serviço de segunda a sexta-feira, em período integral e com participação em todos os grupos e oficinas oferecidas.

A freqüência ao serviço era reduzida de forma gradativa e singular, de acordo com a necessidade de 
cuidados e com a vontade ou necessidade dos sujeitos em freqüentar outros espaços e cuidar de sua vida cotidiana.

Com relação aos participantes da pesquisa, observouse que todos utilizavam o serviço de maneiras diversas. De modo geral, a maior ou menor presença no serviço estava associada às formas de suporte proporcionadas por suas redes de sociabilidade e às suas inserções no trabalho.

Dependendo da demanda apresentada em cada caso, era estabelecido um projeto terapêutico diferenciado. Dois participantes, que estavam no serviço há mais tempo, apresentavam frequência pontual. Na reconstrução de seus percursos, observou-se que ao longo de cada trajeto foram realizadas reformulações nos respectivos projetos terapêuticos, que incluíram momentos de intensificação do cuidado. Quando esses usuários, mesmo estando na etapa de "manutenção" ou tendo deixado de frequentar o serviço, passaram por recaída e voltaram a fazer uso de álcool de forma não controlada, com prejuízos para o desempenho nas atividades cotidianas e reinstalação da síndrome de dependência, foram reincluídos nos cuidados intensivos. Assim, ao voltarem ao CAPSad, tiveram que passar pelas mesmas etapas iniciais de quem estava ingressando no tratamento.

Outro participante, que freqüentava cotidianamente o serviço, tinha um contrato estabelecido com o profissional responsável pela gestão de seu caso que propunha sua ida ao CAPSad quando quisesse ou precisasse, sem dias e horários pré-estabelecidos ou atendimentos previamente agendados. Observou-se que sua circulação pelo serviço de se deu de diversas maneiras. Quando precisava de algum tipo de ajuda, solicitava conversas com algum profissional. Às vezes, participava dos grupos e oficinas. Além disso, havia aprendido algumas técnicas de trabalho com material PET na oficina de reciclagem e ia ao serviço, muitas vezes, para entregar encomendas a profissionais ou outros usuários.

Dentre todos os participantes, este era o que apresentava situação de maior vulnerabilidade social pois estava desempregado, morava sozinho, e relatava empobrecimento em suas atividades cotidianas. Além de cuidar dos afazeres domésticos e passar algumas horas com a filha mais nova, afirmava que saía pouco de casa: "não tenho lugar para onde ir"'(MARQUES, 2010, p. 99).

Observou-se que os participantes que estavam trabalhando frequentaram o CAPSad por períodos mais restritos, com menor presença nas dinâmicas do serviço. Chamou a atenção o fato de que estes usuários eram questionados sobre a opção de trabalhar ao invés de permanecerem freqüentando o serviço. Tal escolha era qualificada, pela equipe, como abandono do tratamento.

A importância dos vínculos com o serviço, com os funcionários e com os demais usuários foi um tema recorrente ao longo do processo de trabalho de campo. Os usuários atribuíam à possibilidade de encontro como as pessoas, profissionais ou demais sujeitos atendidos, o principal sentido do tratamento.

Em certo momento do processo de observação, um usuário chegou ao serviço, circulou pelos espaços e se despediu alguns minutos depois. Perguntamos - "Você não veio participar de nenhum grupo?". A resposta foi - "Não preciso mais. Eu já sei de tudo. Hoje em dia eu venho ao CAPS só para visitar, como uma manutenção, porque eu gosto daqui, eu gosto do pessoal" (MARQUES, 2010, p.102).

Outra usuária foi observada questionando o profissional, gestor de seu caso, se ela poderia mudar o dia em que participava das atividades no CAPS. Ao ser interrogada sobre o motivo do pedido, respondeu: -"de quinta, tem macarrão no almoço e eu não gosto" (MARQUES, 2010, p. 101). Poder-se-ia questionar se ela ia ao CAPS só para o almoço, mas esse não pareceu ser o motivo. Nos grupos em que participava, demonstrava envolvimento e interesse nas atividades realizadas, além de ressaltar a todos o quanto o processo de tratamento provocou mudanças em sua vida. Mas, para ela, parecia não fazer diferença participar da oficina de Tear ou de Reciclagem, nem do grupo de Prevenção de Recaída ou o de Reflexão. Pois, quando questionada sobre a troca dos grupos, sua avaliação residia na percepção sobre sua maior ou menor afinidade com o profissional que coordenava o grupo, e não nos resultados da proposta desenvolvida.

Os participantes da pesquisa apresentavam como particularidade serem sujeitos que aderiram ao tratamento e valorizavam as terapêuticas recebidas. Se no momento de chegada ao serviço não haviam formulado claramente uma imagem acerca do tratamento, o acompanhamento contínuo possibilitou a compreensão sobre aspectos que consideram importantes na construção de seus projetos terapêuticos.

Percebeu-se ainda que algumas de suas concepções iniciais foram modificadas. Antes da chegada ao CAPSad, acreditavam que a única possibilidade de tratamento deveria ser aquela configurada pela internação hospitalar ou em comunidade terapêutica, mas, ao longo de seu processo terapêutico, passaram a valorizar a possibilidade do atendimento substitutivo à internação com a realização de ações no território em que vivem.

Verificou-se que após certo tempo de acompanhamento no serviço, era possível ressignificar e produzir novas demandas. Se no momento de chegada ao serviço não possuíam expectativas claras sobre o tratamento, no cuidado cotidiano puderam perceber necessidades tais como a de 
recuperar os laços familiares e afetivos, trabalhar, estudar, criar vínculos, entre outras. Assim, tais ações, poderiam compor e delinear os projetos terapêuticos dos usuários.

\section{ANÁLISE E DISCUSSÃo}

Embora não se tratasse de objetivo inicial do trabalho, o conhecimento sobre os itinerários percorridos pelos sujeitos possibilitou a reflexão sobre o sentido das práticas de atenção e cuidado à saúde desenvolvidas no serviço. Três aspectos merecem destaque: a demanda pela ampliação de espaços de trocas sociais; a inclusão no trabalho e a importância do serviço como lócus de vínculos e trocas interpessoais.

$\mathrm{Na}$ reconstrução de suas trajetórias, notou-se que os percursos vivenciados evidenciaram que uma das conseqüências da experiência da dependência é a priorização do uso de substâncias psicoativas em detrimento de outras atividades cotidianas, o que provoca o estreitamento no repertório de trocas e intercâmbio social. Assim, coloca-se a necessidade de promover percursos de inclusão em circuitos de trocas materiais e afetivas como estratégia de cuidado. Na participação em circuitos de trocas, os sujeitos podem exercer outros papéis, outras identidades.

Também a inserção no trabalho é um importante fator para o processo de (re)aquisição de direitos, construção de cidadania, aumento da autonomia e da contratualidade nas ações cotidianas. A possibilidade de trabalhar é compreendida como uma "conquista", que leva os usuários a sentirem-se mais confiantes em si e no tratamento realizado.

Contudo, muitas vezes, o serviço apresenta dificuldade em acolher diferentes possibilidades e demandas de adesão ao tratamento de usuários que mantém vínculos ativos de trabalho. Exemplos colhidos no cotidiano mostram que a impossibilidade de freqüentar a totalidade dos grupos propostos na fase inicial do tratamento tende a ser interpretada pela equipe como dificuldade de adesão e não como uma real dificuldade para aqueles que tentam administrar, concomitantemente, a adesão ao tratamento e a manutenção do vínculo de trabalho. Observou-se, também, situações onde usuários, após conseguirem vincular-se a novos trabalhos, eram criticados por faltarem aos grupos de atendimento. Tais exemplos remetem a necessidade de questionamento do modelo do serviço centrado em procedimentos e pouco sensível às demandas e mudanças na vida cotidiana dos sujeitos.

A terceira questão se coloca como complementar às anteriores e diz respeito ao papel dos serviços como referência para o desenvolvimento de vínculos e novas relações interpessoais. O relato sobre os itinerários e a observação de campo mostrou que, em muitos momentos, a freqüência cotidiana ao serviço se dava como possibilidade de rever amigos, conversar, planejar encontros e atividades fora do serviço e não como validação e/ou reconhecimento do papel terapêutico dos grupos propostos. Houve momentos onde se percebia que usuários optavam por faltarem aos grupos por considerarem mais importante alimentarem as relações que ocorriam, de forma difusa, no serviço.

Essa questão merece atenção particular das equipes, pois não podem ser interpretadas de forma unívoca como estratégias diversionistas ou de fuga e recusa ao tratamento, e sim como movimentos que podem refletir atitudes ativas dos sujeitos na reconstrução de percursos de convivência social. São muitos os aspectos ligados às demandas complexas dos usuários que escapam da atenção da equipe quando esta opta por uma forma de organização do serviço centrada em um repertório pré-estabelecido de procedimentos que, dificilmente, são negociados com os sujeitos interessados.

Não observamos, no contexto estudado, a preocupação clara com os aspectos apontados. Falta assim, maior desenvolvimento de estratégias que envolvam a comunidade, que explorem os recursos existentes e criem outros. Os serviços de saúde, equipamentos comunitários (igrejas, associações de bairro, ginásios esportivos, escolas), usuários e suas famílias são todos recursos a serem utilizados. O CAPSad acaba sendo um espaço importante de convívio, mas não pode ser o único lugar de pertencimento no qual as trocas sociais sejam possíveis (SARACENO, 1998).

Como articulador das ações de saúde mental de um determinado território, o CAPSad deve funcionar como um serviço disponível e atento a gerar oportunidades de trocas de recursos materiais e afetivos e construir, junto com os sujeitos, uma linha de produção de cuidado que os acompanhe nos serviços e instituições que disponham dos recursos e tecnologias que necessitem, efetivando o desafio da integralidade em suas ações.

\section{CONSIDERAÇÕES FINAIS}

Os serviços voltados a essa população, por vezes, acabam incorporando práticas orientadas por uma compreensão linear, reducionista e até mesmo moralista. Tendem a simplificar o sofrimento dos sujeitos em categorias nosológicas definidas que se tornam a base para a formulação do processo terapêutico. Para a dependência, a meta a ser atingida é a abstinência, que orienta e define as ações profissionais. Assim, a existência dos sujeitos é reduzida a uma patologia, transformando o usuário em um objeto da intervenção profissional e não um sujeito capaz de 
produzir sentido e construir projetos. Esse modo de pensar e agir reforça a construção de modos de cuidar centrados em procedimentos e desconectados dos contextos reais e concretos de vida dos sujeitos atendidos (SARACENO, 1998; MERHY, 2005; CECILIO, 2006).

Essa postura também foi observada no contexto estudado, uma vez que a equipe do serviço oferece aos sujeitos um rol pré-definido de ações, configurado em atendimentos especializados, oficinas terapêuticas, dispensação de medicação, entre outros. Essa oferta define que todos os sujeitos devam, em um primeiro momento, participar de todos os grupos e oficinas existentes e só após se determina procedimentos mais específicos para cada caso.

Embora essa proposta possa trazer benefícios ao processo terapêutico dos sujeitos, faz-se necessário criticar sua lógica que adequa suas demandas às ofertas disponíveis no serviço. Tal lógica oferece respostas simples e universais à demandas complexas do sofrimento e da existência dos sujeitos. Pode, com isso, gerar a desassistência daqueles que não se "enquadram" naquilo que é oferecido no serviço, que são considerados "refratários" ou que abandonam o tratamento por não encontrarem respostas efetivas para seus problemas. Tal como propõe Merhy (2005), defendemos a inversão dessa lógica: é o sujeito e seu complexo mundo de necessidades que deve orientar a construção do projeto terapêutico. Se o processo de trabalho é orientado apenas a partir de ofertas pré-definidas, às quais os sujeitos devem se adequar, perde-se a possibilidade da riqueza e potência do encontro entre profissional e usuário, momento singular no qual podem ser desveladas as necessidades concretas e simbólicas dos sujeitos.

Os projetos terapêuticos devem ser resultado da articulação de todos os sujeitos envolvidos e de todos os recursos disponíveis (Franco, Magalhães Jr, 2004), garantindo um cuidado contínuo e permanente, que extrapole a meta da manutenção da abstinência e que acompanhe e referencie os sujeitos pelo tempo que demandarem.

MARQUES, A. L. M.; MÂNGIA, E. F. Organization and care practices: a study on psychosocial care center for users of alcohol and other drugs. Rev. Ter. Ocup. Univ. São Paulo, v. 22, n. 3, p. 229-237, set./dez. 2011.

\begin{abstract}
This article aims to present the organization and practices developed in a Psychosocial Care Center to alcohol and other drugs users (CAPSad), in order to give visibility to this type of service, recently implemented in Brazil, which requires improvement in its various aspects. It also aims to reflect on the actions taken for the construction of therapeutic projects to the service users. The contents presented are part of the dissertation "Therapeutic Itineraries of individuals with problems in consequence of the use of alcohol in a Psychosocial Care Center." The qualitative research was developed in the period from January to March 2009, at CAPSad "Travessia". It was concluded that the CAPSad should run as a service available and attentive to generate opportunities for the exchange of material and emotional resources and produce, together with the subjects, comprehensive care and focused on their needs.
\end{abstract}

KEY WORDS: Mental health services; Drug users/psychology; Alcoholism/psychology.

\title{
REFERÊNCIAS
}

BRASIL. Ministério da Saúde. A política do Ministério da Saúde para a atenção integral a usuários de álcool e outras drogas. Brasília, 2003. Série B. Textos Básicos de Saúde.

BRASIL. Ministério da Saúde. Portaria n.2197, 04 de outubro de 2004. Redefine e amplia a atenção integral para usuários de álcool e outras drogas, no âmbito do Sistema Único de Saúde - SUS, e dá outras providências. Diário Oficial da União, Brasília, 2004c.

CECILIO, L. C. O. As Necessidades de saúde como conceito estruturante na luta pela integralidade e equidade na atenção em saúde. In: PINHEIRO, R.; MATTOS, R. A. (Orgs.). Os sentidos 
da integralidade na atenção e no cuidado à saúde. Rio de Janeiro: UERJ,IMS/ ABRASCO, 2006. p. 115-128.

FIGLIE, N. B.; LARANJEIRA, R. Gerenciamento de caso aplicado ao tratamento da dependência do álcool. Rev. Bras. Psiquiatr., v. 26, n. 1, p. 63-67, 2004.

FRANCO, T. B.; MAGALHÃES Jr, H. M. Integralidade na assistência à saúde: a organização das linhas do cuidado. In: MERHY, et al. (Orgs.). O trabalho em saúde: olhando e experenciando o SUS no cotidiano. São Paulo: Hucitec, 2004.

FUNDAÇÃO SISTEMA ESTADUAL DE ANÁLISE DE DADOS (SEADE). Índice paulista de vulnerabilidade social. Disponível em: <http://www.seade.gov.br/produtos/ipvs/>. Acesso em 20 jun. 2009.

MARQUES, A. L. M. Itinerários terapêuticos de sujeitos com problemáticas decorrentes do uso de álcool. São Paulo, 2010. $139 f$.
Dissertação (mestrado) - Faculdade de Medicina, Universidade de São Paulo.

MERHY, E. E. Engravidando palavras: o caso da integralidade. In: CONGRESSO DA REDE UNIDA; 2005; Belo Horizonte, MG. Disponível em: <http:/www.uff.br/saudecoletiva/professores/ merhy/capitulos-06.pdf>.

ORGANIZAÇÃO MUNDIAL DA SAÚDE (OMS), Organização Pan-americana da Saúde (OPAS). Relatório sobre a saúde no mundo-2001. Saúde Mental: nova concepção, nova esperança. Rio de Janeiro: Gráfica Brasil, Organização Mundial da Saúde, 2001.

SANTANA DE PARNAÍBA. Centro de Atenção Psicossocial Álcool e Drogas "Travessia". Relatório anual CAPSad "Travessia"2008. 2009. [circulação interna]

SARACENO, B. La cittadinanza come forma di tolleranza. Rio de Janeiro, 1998. Disponível em: <http://www.exclusion.net>. 